\title{
OPEN A low pKa ligand inhibits cancer-associated pain in mice by activating peripheral mu-opioid receptors
}

Ana Baamonde ${ }^{1}$, Luis Menéndez ${ }^{1}$, Sara González-Rodríguez ${ }^{1}$, Ana Lastra ${ }^{1}$, Viola Seitz 2,3, Christoph Stein $\mathbb{1}^{2}$ \& Halina Machelska $\mathbb{1}^{2}$

The newly designed fentanyl derivative [( \pm )- $\mathrm{N}$-(3-fluoro-1-phenethylpiperidine-4-yl)-N-phenyl propionamide] (NFEPP) was recently shown to produce analgesia selectively via peripheral mu-opioid receptors (MOR) at acidic $\mathrm{pH}$ in rat inflamed tissues. Here, we examined the $\mathrm{pH}$-dependency of NFEPP binding to brain MOR and its effects on bone cancer-induced pain in mice. The $\mathrm{IC}_{50}$ of NFEPP to displace bound $\left.{ }^{3} \mathrm{H}\right]$-DAMGO was significantly higher compared to fentanyl at $\mathrm{pH} 7.4$, but no differences were observed at $\mathrm{pH} 5.5$ or 6.5 . Intravenous NFEPP $(30-100 \mathrm{nmol} / \mathrm{kg})$ or fentanyl (17-30 nmol/kg) inhibited heat hyperalgesia in mice inoculated with B16-F10 melanoma cells. The peripherally-restricted opioid receptor antagonist naloxone-methiodide reversed the effect of NFEPP $(100 \mathrm{nmol} / \mathrm{kg})$, but not of fentanyl $(30 \mathrm{nmol} / \mathrm{kg})$. The antihyperalgesic effect of NFEPP was abolished by a selective MOR- (cyprodime), but not delta- (naltrindole) or kappa- (nor-binaltorphimine) receptor antagonists. Ten-fold higher doses of NFEPP than fentanyl induced maximal antinociception in mice without tumors, which was reversed by the non-restricted antagonist naloxone, but not by naloxone-methiodide. NFEPP also reduced heat hyperalgesia produced by fibrosarcoma- (NCTC 2472) or prostate cancer-derived (RM1) cells. These data demonstrate the increased affinity of NFEPP for murine MOR at low $\mathrm{pH}$, and its ability to inhibit bone cancer-induced hyperalgesia through peripheral MOR. In mice, central opioid receptors may be activated by ten-fold higher doses of NFEPP.

A large number of painful syndromes are driven by peripheral sensory neurons $s^{1,2}$ and are typically accompanied by inflammation with tissue acidosis ${ }^{3,4}$. A prominent example is pain associated with tumors, which exhibit a low extracellular $\mathrm{pH}^{5}$. In bone cancer, different factors such as augmented glycolysis due to excessive cell proliferation ${ }^{6}$ or enhanced osteoclast activity may account for the increased acidity and inflammation ${ }^{7}$. $\mathrm{pH}$ values as low as 4.5 may be reached at the resorptive microenvironment ${ }^{8}$. The diminished $\mathrm{pH}$ is also a cause of bone cancerinduced pain through the activation of transient receptor potential cation channel subfamily $\mathrm{V}$ member 1 and acid-sensing ion channel 3 in peripheral sensory neurons ${ }^{9-11}$. Under inflammatory conditions, peripheral opioid receptors and their signaling pathways are upregulated and can mediate relevant opioid analgesia in animals and humans ${ }^{12,13}$. We have recently shown in rats that the agonist $( \pm)-N$-(3-fluoro-1-phenethylpiperidine-4-yl)$\mathrm{N}$-phenylpropionamide (NFEPP), which was designed to selectively activate mu-opioid receptors (MOR) at low $\mathrm{pH}$, ameliorates inflammatory, neuropathic and abdominal pain, but does not elicit side effects typically mediated by MOR exposed to physiological $\mathrm{pH}$ in the intestinal myenteric plexus or central nervous system (CNS) ${ }^{14-16}$. It appears that a ligand's $\mathrm{pKa}$ should be close to the $\mathrm{pH}$ of damaged tissue to obtain antinociception without adverse effects such as respiratory depression, sedation, reward and constipation ${ }^{17,18}$.

Here, we explore the $\mathrm{pH}$-dependency of NFEPP binding to mouse brain MOR and assess the antihyperalgesic effects of NFEPP in murine models of bone cancer-induced pain. To this end, we tested the effects of NFEPP on pain in mice intratibially inoculated with melanoma B16-F10 cells. This cell line induces mixed osteoblastic/

\footnotetext{
${ }^{1}$ Laboratorio de Farmacología, Facultad de Medicina, Instituto Universitario de Oncología del Principado de Asturias (IUOPA), Instituto de Investigación Sanitaria del Principado de Asturias (ISPA), Universidad de Oviedo, C/Julián Clavería 6, 33006 Oviedo, Asturias, Spain. ${ }^{2}$ Department of Experimental Anesthesiology, Charité-Universitätsmedizin Berlin, Campus Benjamin Franklin, Hindenburgdamm 30, 12203 Berlin, Germany. 3Present address: Institute of Biochemistry and Biology, University of Potsdam, Karl-Liebknecht-Str. 24-25, 14474 Potsdam, Germany. ${ }^{\boxplus e m a i l}$ arbaiza@uniovi.es
} 

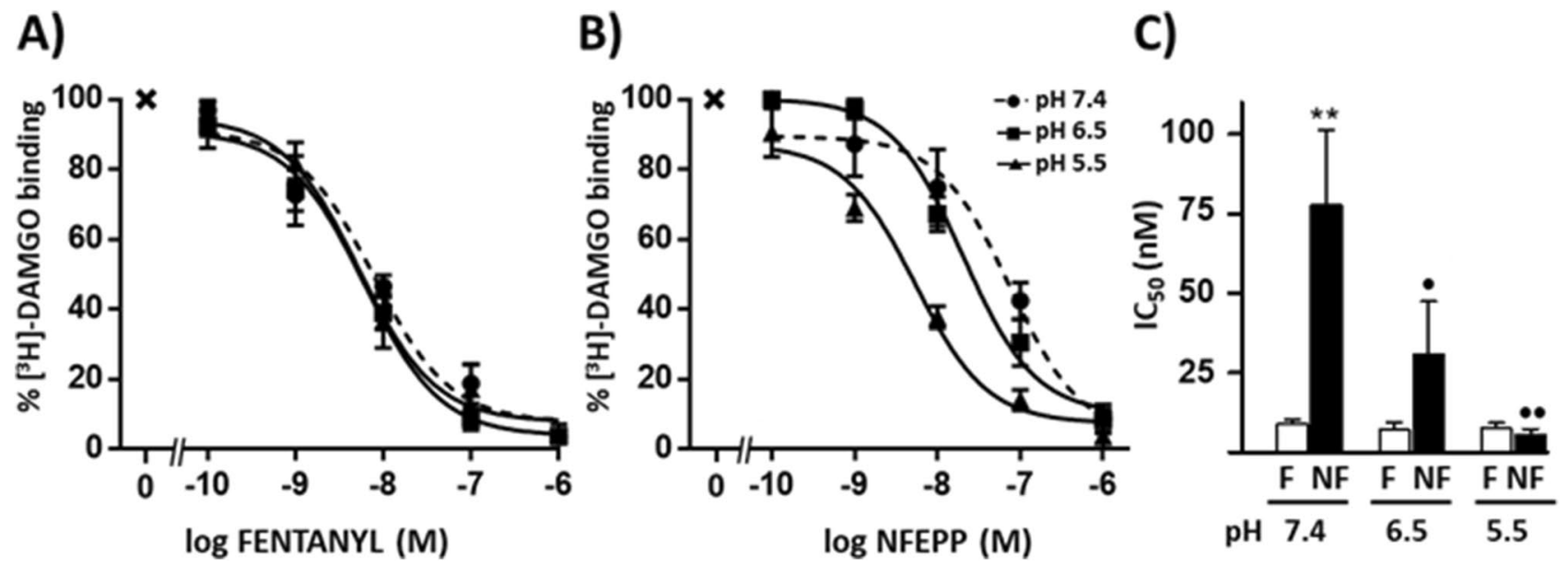

Figure 1. Competition of fentanyl and NFEPP with specific $\left[{ }^{3} \mathrm{H}\right]-\mathrm{DAMGO}(4 \mathrm{nM})$ binding in mouse brain membranes at $\mathrm{pH} 7.4,6.5$ and 5.5. Concentration-response effects of (A) fentanyl and (B) NFEPP, where $\mathrm{x}$ represents the total specific binding in the absence of fentanyl or NFEPP. (C) $\mathrm{IC}_{50}$ values of fentanyl (F) and NFEPP (NF). Means \pm SEM ( $\mathrm{n}=6$ in $\mathrm{pH} 7.4$ groups, $\mathrm{n}=5$ per group for other $\mathrm{pH}$ values) are represented. ${ }^{*} P<0.01$, compared to fentanyl at the same $\mathrm{pH} ; \bullet P<0.05, \bullet \bullet P<0.01$ compared to NF at $\mathrm{pH} 7.4$, two-way ANOVA and Tukey's test.

osteoclastic activity that causes bone osteolysis and extracellular acidity ${ }^{19}$. Because the analgesic efficacy of some compounds can depend on the type of tumor cells ${ }^{20}$, we also evaluated mice treated with fibrosarcoma NCTC 2472 cells or RM1 cells derived from prostate carcinoma.

\section{Results}

Binding of NFEPP to brain MOR is increased at low $\mathrm{pH}$. Competition studies were performed in the presence of a fixed concentration of selective MOR ligand $\left[{ }^{3} \mathrm{H}\right]-\mathrm{DAMGO}\left(\left[\mathrm{D}-\mathrm{Ala}^{2}, \mathrm{~N}-\mathrm{Me}-\mathrm{Phe}{ }^{4}, \mathrm{Gly}^{5}\right.\right.$-ol]enkephalin; $4 \mathrm{nM}$ ) at different $\mathrm{pH}$ values. The binding of $\left[{ }^{3} \mathrm{H}\right]$-DAMGO to brain membranes was dose-dependently inhibited by fentanyl (Fig. 1A) and NFEPP (Fig. 1B) between $10^{-10}$ and $10^{-6} \mathrm{M}$. Whereas the concentrations of fentanyl that inhibited $\left[{ }^{3} \mathrm{H}\right]$-DAMGO binding by $50 \%$ (inhibitory concentration 50 ; $\mathrm{IC}_{50}$ ) were similar at all investigated $\mathrm{pH}$ values $(7.4,6.5,5.5)$, the corresponding $\mathrm{IC}_{50}$ values of NFEPP decreased progressively at acidic pH (Fig. 1C; drug: $\mathrm{F}_{1,26}=8.12, P=0.009$; $\mathrm{pH}: \mathrm{F}_{2,26}=4.46, P<0.022$; drug $\mathrm{x} \mathrm{pH}: \mathrm{F}_{2,26}=4.04, P=0.03$ ). At physiologic $\mathrm{pH}$ (7.4), NFEPP's IC $\mathrm{I}_{50}$ was significantly (one order of magnitude) higher than that of fentanyl $(P<0.01)$. In contrast, the $\mathrm{IC}_{50}$ values of the both drugs were similar at pH $6.5(P=0.81)$ and $\mathrm{pH} 5.5(P>0.99)$ (Fig. 1C).

Fentanyl and high doses of NFEPP produce antinociception in mice without tumors. Mice intratibially inoculated with killed B16-F10 melanoma cells do not develop tumors and were used as controls. One week after inoculation with these cells ${ }^{21}$, the intravenous (i.v.) administration of fentanyl (30-100 nmol/ $\mathrm{kg}$ ) or NFEPP (100-1000 nmol/kg) evoked a dose-dependent antinociceptive response in the inoculated limbs (Fig. 2A; fentanyl: $\mathrm{F}_{3,16}=54.06, P<0.0001$; NFEPP: $\mathrm{F}_{3,16}=69.27, P<0.0001$ ). NFEPP produced antinociception at doses of 300-1000 nmol/kg i.v., i.e. at about 6-tenfold higher doses compared to fentanyl (Fig. 2A). Similar effects were observed in the contralateral limbs (data not shown).

To analyze the involvement of central or peripheral opioid receptors, we used non-selective opioid receptor antagonists, naloxone hydrochloride (naloxone) and naloxone-methiodide (NLX-MET). Naloxone acts at both central and peripheral opioid receptors, whereas NLX-MET acts at peripheral opioid receptors, since it does not readily cross the blood-brain barrier ${ }^{22-25}$. Naloxone $(1 \mathrm{mg} / \mathrm{kg})$ injected subcutaneously (s.c.) at the neck completely suppressed the antinociceptive effects evoked by fentanyl (100 nmol/kg i.v.) or NFEPP (1000 nmol/ $\mathrm{kg}$ i.v.) $(P>0.99$, naloxone with solvent vs. naloxone with fentanyl or NFEPP). In contrast, NLX-MET $(1 \mu \mathrm{g})$ injected s.c. in the calf (over the tibia site inoculated with killed B16-F10 cells) did not modify the effects of either agonist $(P<0.0001$, NLX-MET with solvent vs. NLX-MET with fentanyl or NFEPP; Fig. 2B).

Fentanyl acting centrally and NFEPP acting at peripheral MOR inhibit hyperalgesia in tumor-bearing mice. The intratibial inoculation with live B16-F10 cells provoked the development of tumors leading to unilateral thermal hyperalgesia 1 week later, as previously described ${ }^{21}$. Thus, withdrawal latencies in tumor-inoculated limbs were significantly lower than in contralateral, non-tumoral limbs $(P<0.001$; Fig. 3A). The i.v. administration of fentanyl $(10-100 \mathrm{nmol} / \mathrm{kg})$ dose-dependently inhibited hyperalgesia in the ipsilateral, tumor-bearing $\operatorname{limb}\left(\mathrm{F}_{4,20}=21.87, P<0.0001\right)$. At a dose of $100 \mathrm{nmol} / \mathrm{kg}$ i.v., fentanyl exerted similar (almost maximal) increases in withdrawal latencies in both tumor-bearing and contralateral, tumor-free limbs $(P<0.0001$ vs. solvent; Fig. $3 \mathrm{~A})$. In contrast, only the latencies measured in tumor-bearing limbs were dosedependently elevated after i.v. NFEPP $(10-100 \mathrm{nmol} / \mathrm{kg})\left(\mathrm{F}_{3,16}=9.083, P=0.001\right)$ and no effects were observed in contralateral, tumor-free limbs $\left(\mathrm{F}_{3,17}=2.101, P=0.138\right)$ (Fig. 3A). 

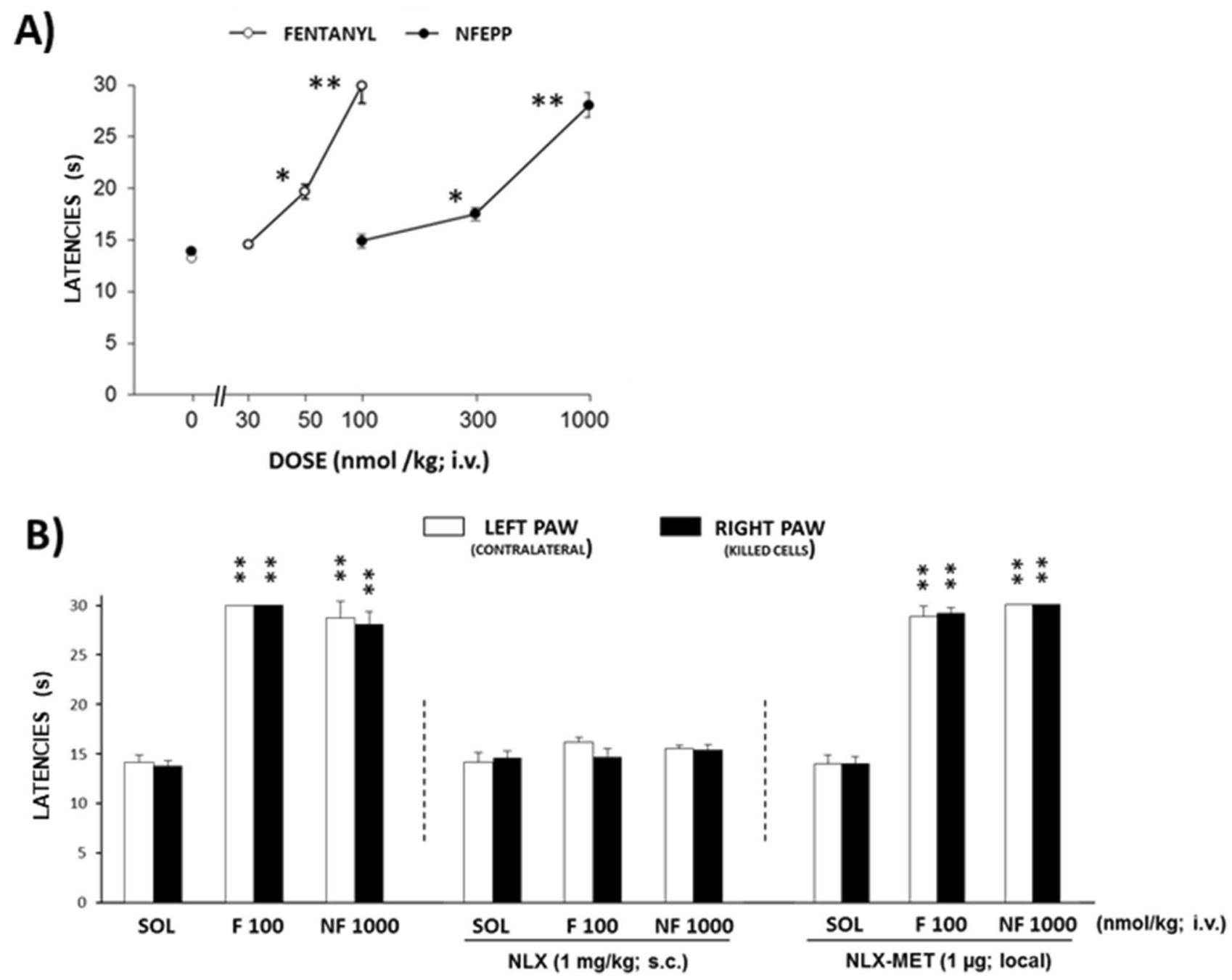

Figure 2. Effects of i.v. fentanyl and NFEPP on heat hyperalgesia in mice inoculated with killed B16-F10 cells. (A) Dose-response effects of fentanyl (30-100 nmol/kg) and NFEPP (100-1000 nmol/kg) on ipsilateral paw withdrawal latencies ( $\mathrm{n}=5$ per group). ${ }^{\star} P<0.05,{ }^{* *} P<0.01$ compared to solvent $(0 \mathrm{nmol} / \mathrm{kg})$-treated mice, one-way ANOVA and Dunnett's $t$ test. (B) Systemic naloxone (NLX; $1 \mathrm{mg} / \mathrm{kg}$ s.c. at the neck) but not the local injection of naloxone-methiodide (NLX-MET; $1 \mu \mathrm{g}$ s.c. in the calf) into the inoculated limb inhibited the antinociceptive effect of fentanyl (F) and NFEPP (NF) ( $n=7$ in F+NLX-MET group, $n=5$ per group for other treatments). ${ }^{*} P<0.01$ compared to the corresponding paw of the respective solvent (SOL)-treated mice, twoway ANOVA and Tukey's test. All data are means \pm SEM. For clarity, in the graphs a maximal number of two symbols of significancy are represented (the exact values are stated in the results section).

Systemic naloxone ( $1 \mathrm{mg} / \mathrm{kg}$ s.c. at the neck) completely reversed the antihyperalgesic effects induced by both fentanyl $(30 \mathrm{nmol} / \mathrm{kg}$ i.v. $)$ and NFEPP $(100 \mathrm{nmol} / \mathrm{kg}$ i.v. $)$ in inoculated limbs $(P>0.99$, naloxone with solvent vs. naloxone with fentanyl or NFEPP; Fig. 3B). The effects of NLX-MET were assessed against two different doses of the agonists: an antihyperalgesic dose, which restores latencies up to values measured in healthy mice, and an antinociceptive dose that produces an increase in withdrawal latencies above those measured in healthy mice, up to cut-off values. The effect evoked by an antihyperalgesic dose of fentanyl $(30 \mathrm{nmol} / \mathrm{kg}$ i.v. $)$ was not modified by the peritumoral (s.c. over tibial tumoral mass) administration of NLX-MET $(1 \mu \mathrm{g})(P=0.954)$. In contrast, the antihyperalgesic effect evoked by $100 \mathrm{nmol} / \mathrm{kg}$ (i.v.) NFEPP was dose-dependently inhibited by NLX-MET $(0.1-1 \mu \mathrm{g})$ applied peritumorally $\left(\mathrm{F}_{4,20}=36.65, P<0.0001\right)$, but not contralaterally $(1 \mu \mathrm{g}$ s.c. in the calf) $(P=0.9998)$ (Fig. 3B). Besides, the bilateral antinociceptive effects evoked by high doses of either fentanyl $(100 \mathrm{nmol} / \mathrm{kg}$ i.v. $)$ or NFEPP $(1000 \mathrm{nmol} / \mathrm{kg}$ i.v. $)$ were unaffected by the peritumoral administration of NLX-MET $(1 \mu \mathrm{g})(P=0.801$ and $P>0.9999$, respectively; Fig. 3C).

Systemic (s.c. at the neck) administration of the MOR selective antagonist cyprodime ( $1 \mathrm{mg} / \mathrm{kg}$ s.c.) prevented the antihyperalgesic effect of NFEPP $(100 \mathrm{nmol} / \mathrm{kg}$ i.v. $)(P<0.0001)$, whereas the selective antagonists of deltaopioid receptors (DOR) naltrindole $(0.1 \mathrm{mg} / \mathrm{kg}$ s.c. $)$ or of kappa-opioid receptors (KOR) nor-binaltorphimine (10 mg/kg s.c.) had no effects $(P=0.7735$ and $P=0.9710$, respectively; Fig. $3 \mathrm{D})$. 
A)

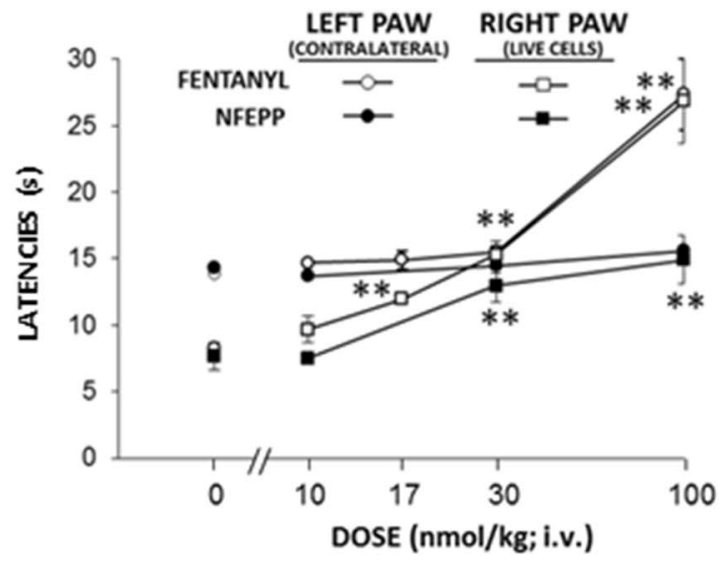

B)
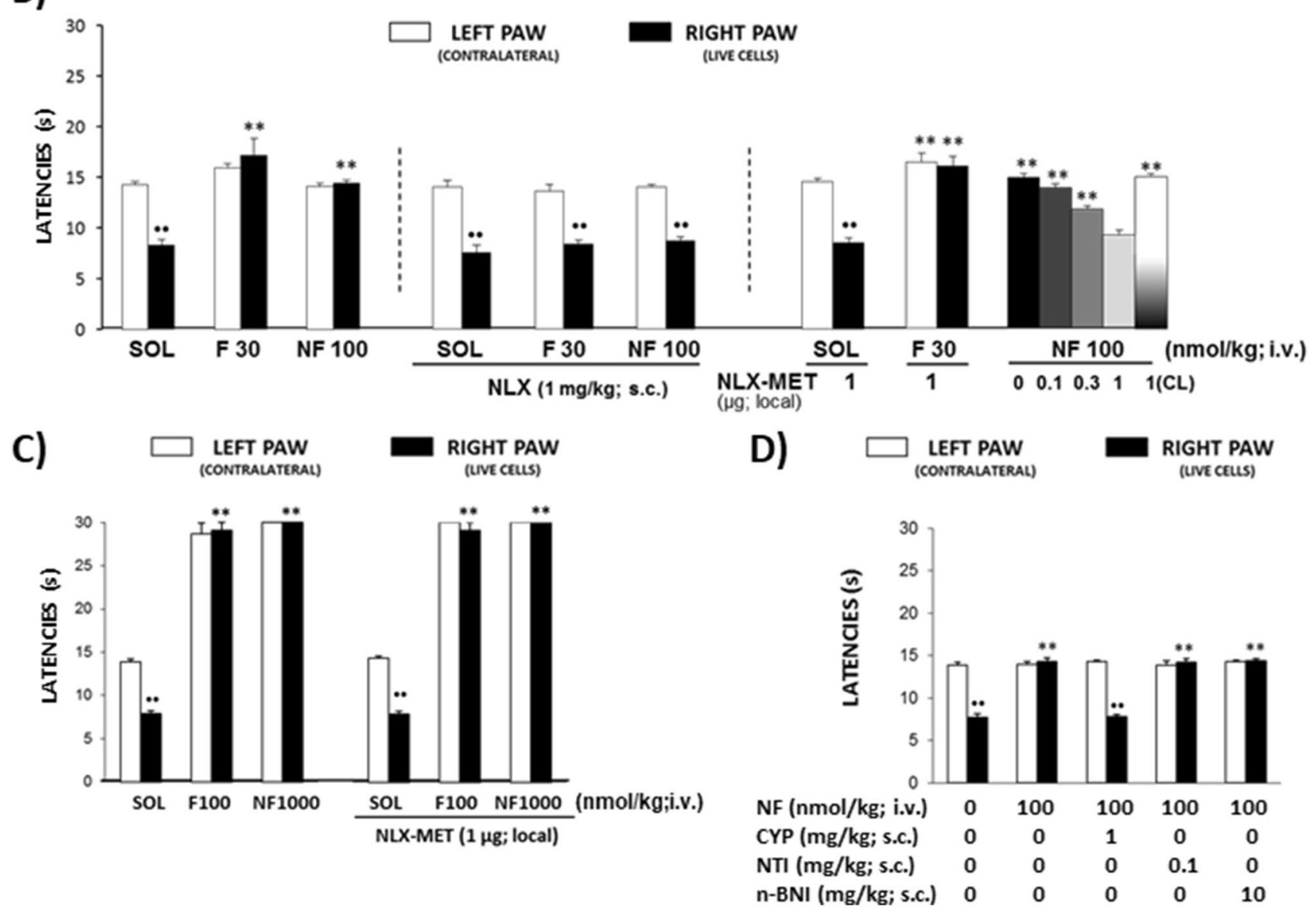

Figure 3. Effects of i.v. fentanyl and NFEPP on heat hyperalgesia in mice inoculated with live B16-F10 cells. (A) Dose-response effects of fentanyl and NFEPP (both at 10-100 nmol/kg) $(\mathrm{n}=6$ in NFEPP $30 \mathrm{nmol} / \mathrm{kg}$ group, $\mathrm{n}=5$ per group for other treatments). (B) Systemic naloxone (NLX; $1 \mathrm{mg} / \mathrm{kg}$ s.c. at the neck), but not peritumoral naloxone-methiodide (NLX-MET; $1 \mu \mathrm{g}$ local), inhibited the effect of i.v. fentanyl (F; $30 \mathrm{nmol} / \mathrm{kg}$ ). Both NLX (1 mg/kg) and NLX-MET (0.1-1 $\mu \mathrm{g})$ reversed the effect of NFEPP (NF; $100 \mathrm{nmol} / \mathrm{kg})$. NLX-MET $(1 \mu \mathrm{g}$ local) had no effect when injected into non-inoculated, contralateral limb (CL) $(\mathrm{n}=6$ in solvent [SOL] group, $n=8$ in $F+$ NLX-MET group, $n=5$ per group for other treatments). (C) Peritumoral NLX-MET (1 $\mu \mathrm{g}$ local) did not modify antinociceptive effects evoked by high doses of fentanyl (F; $100 \mathrm{nmol} / \mathrm{kg}$ ) or NFEPP (NF; $1000 \mathrm{nmol} / \mathrm{kg}$ ) ( $\mathrm{n}=6$ in SOL + NLX-MET and F + NLX-MET groups, $\mathrm{n}=5$ per group for other treatments). (D) Cyprodime (CYP; $1 \mathrm{mg} / \mathrm{kg})$, but not naltrindole (NTI; $0.1 \mathrm{mg} / \mathrm{kg})$ or nor-binaltorphimine (n-BNI; $10 \mathrm{mg} /$ $\mathrm{kg})$, injected s.c. at the neck, inhibited the effects of NF $(100 \mathrm{nmol} / \mathrm{kg})(\mathrm{n}=5$ per group $)$. In $(\mathbf{A}, \mathbf{B}), \bullet \bullet P<0.01$ compared to the corresponding left paw, unpaired Student's $t$ test; ${ }^{* *} P<0.01$ compared to solvent (SOL)-treated mice, one-way ANOVA and Dunnett's $t$ test. In $(\mathbf{C}, \mathbf{D}), \bullet \bullet P<0.01$ compared to the corresponding left paw, unpaired Student's $t$ test; ${ }^{* \star} \mathrm{P}<0.01$ compared to the corresponding paw in solvent (SOL)-treated mice, two-way ANOVA and Tukey's test. All data are means \pm SEM. For clarity, in the graphs a maximal number of two symbols of significancy are represented (the exact values are stated in the results section). 
A)

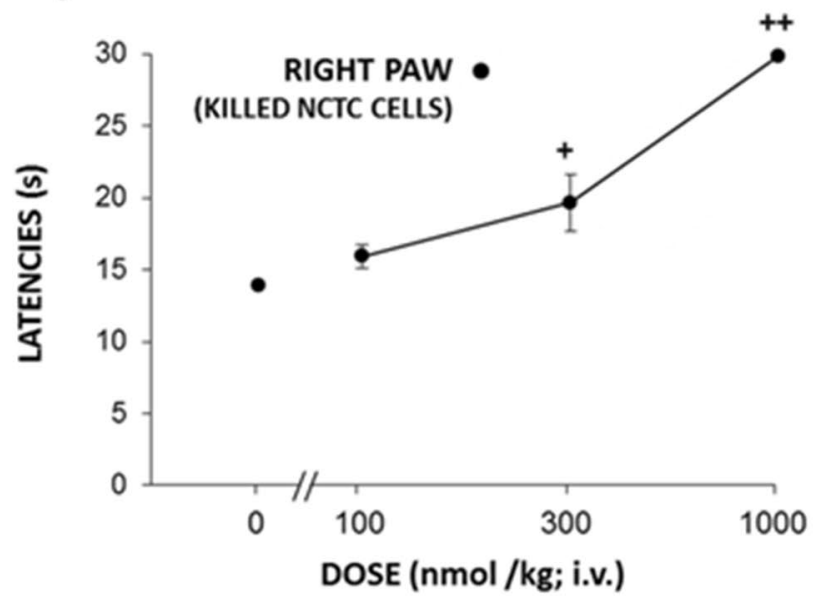

B)

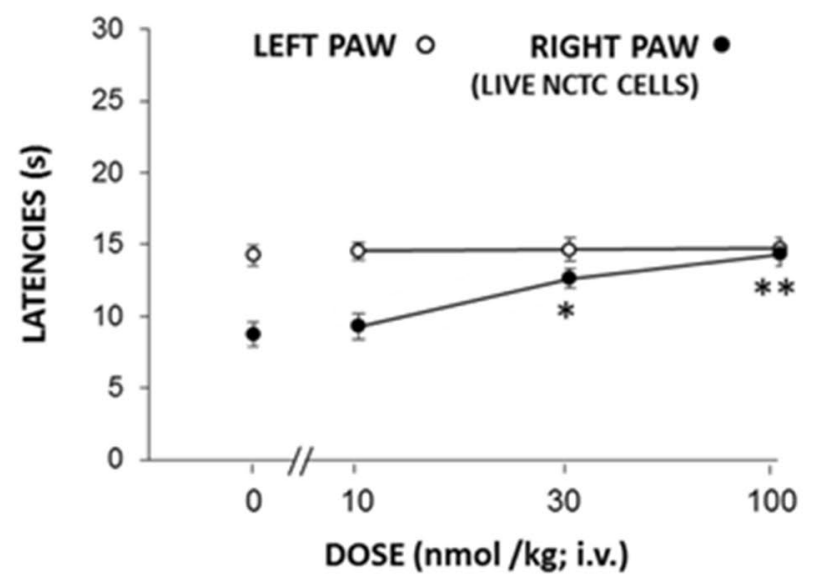

C)

D)
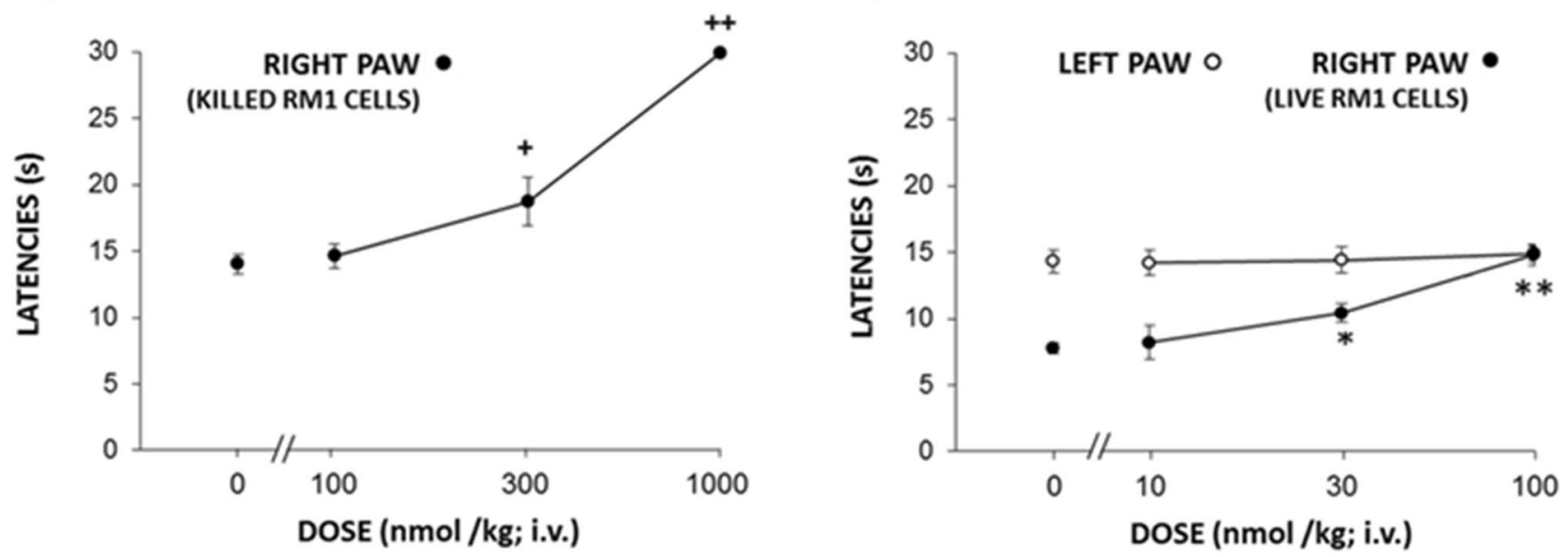

Figure 4. Effects of i.v. NFEPP (10-1000 mg/kg) on heat hyperalgesia in mice inoculated with NCTC 2472 or RM1 cells. Effects in mice inoculated with killed NCTC 2472 cells ( $\mathrm{n}=8$ in $100 \mathrm{nmol} / \mathrm{kg}$ group, $\mathrm{n}=7$ in $300 \mathrm{nmol} / \mathrm{kg}$ group, $\mathrm{n}=5$ per group for other treatments) (A) or RM1 cells ( $\mathrm{n}=5$ per group) (C), or in tumorbearing mice inoculated with live NCTC 2472 cells $(n=6$ in $30 \mathrm{nmol} / \mathrm{kg}$ group, $n=5$ per group for other treatments) (B) or RM1 cells ( $\mathrm{n}=6$ in $100 \mathrm{nmol} / \mathrm{kg}$ group, $\mathrm{n}=7$ per group for other treatments) $(\mathrm{D}){ }^{+} P<0.05$, ${ }^{++} P<0.01$, compared to solvent $(0 \mathrm{nmol} / \mathrm{kg})$-treated mice $(\mathbf{A}, \mathbf{C}) ;{ }^{\star} P<0.05$, ${ }^{\star *} P<0.01$, compared to the solventtreated mice in the right paw, one-way ANOVA and Dunnett's $t$ test $(\mathbf{B}, \mathbf{D})$. All data are means \pm SEM. For clarity, in the graphs a maximal number of two symbols of significancy are represented (the exact values are stated in the results section).

Effects of NFEPP on hyperalgesia evoked by intratibial inoculation with NCTC 2472 or RM1 cells. Four weeks after inoculation with killed NCTC 2472 fibrosarcoma cells ${ }^{26}$ (Fig. 4A) or 2 weeks after inoculation with killed RM1 prostate carcinoma cell $\mathrm{s}^{27}$ (Fig. 4C), which did not induce tumors, high doses of i.v. NFEPP $(300-1000 \mathrm{nmol} / \mathrm{kg})$ produced antinociceptive effects in inoculated limbs $\left(\mathrm{F}_{3,21}=25.40, P<0.0001\right.$ for NCTC 2472 and $\mathrm{F}_{3,16}=178.4, P<0.0001$ for RM1 cells). Mice bearing tumors in response to the inoculation of live NCTC 2472 (Fig. 4B) or RM1 cells (Fig. 4D) developed unilateral thermal hyperalgesia that was inhibited by tenfold lower doses of i.v. NFEPP $(30-100 \mathrm{nmol} / \mathrm{kg})\left(\mathrm{F}_{3,17}=21.75, P<0.0001\right.$ for NCTC 2472 cells and $\mathrm{F}_{3,23}=71.23, P<0.0001$ for RM1 cells). No effects were observed in contralateral, tumor free limbs at these doses $\left(\mathrm{F}_{3,17}=0.23, P=0.88\right.$ for NCTC 2472 cells and $\mathrm{F}_{3,23}=1.802, P=0.17$ for RM1 cells) (Fig. $\left.4 \mathrm{~B}, \mathrm{D}\right)$.

\section{Discussion}

We show here that the fentanyl derivative NFEPP preferentially binds MOR at acidic $\mathrm{pH}$ values in mouse brain membranes and that its systemic (i.v.) administration alleviates hyperalgesia in mice bearing bone tumors by acting at peripheral MOR in the injured tissue.

Similar binding characteristics of NFEPP were recently demonstrated in homogenates of MOR-transfected human embryonic kidney (HEK) 293 cells $^{14}$ and rat brain ${ }^{15}$. Here, we examined mouse brain membranes by comparing the effects of NFEPP and fentanyl on the binding of the selective MOR agonist $\left[{ }^{3} \mathrm{H}\right]-\mathrm{DAMGO}$ to 
MOR. Fentanyl displaced $\left[{ }^{3} \mathrm{H}\right]$-DAMGO binding at nM concentrations, in accordance with previous data ${ }^{28}$. Its affinity for MOR was similar at all $\mathrm{pH}$ values studied $\left(7.4,6.5\right.$ and 5.5). In contrast, the $\mathrm{IC}_{50}$ values of NFEPP that displaced $\left[{ }^{3} \mathrm{H}\right]$-DAMGO binding progressively decreased as the acidity of the milieu increased, reflecting an improved affinity of NFEPP to opioid receptors at low $\mathrm{pH}$. Thus, while the $\mathrm{IC}_{50}$ values of NFEPP and fentanyl were similar at $\mathrm{pH} 5.5$, the $\mathrm{IC}_{50}$ value of NFEPP was substantially greater than that of fentanyl at physiologic $\mathrm{pH}$. These results are in line with those previously reported in MOR-transfected HEK 293 cells $^{14}$ and rat brain membranes ${ }^{15}$.

In coherence with the results of binding experiments, NFEPP showed lower potency than fentanyl to evoke antinociception in uninjured mice. In these mice NFEPP only induced considerable effects at doses tenfold higher $(1000 \mathrm{nmol} / \mathrm{kg})$ compared to fentanyl $(100 \mathrm{nmol} / \mathrm{kg})$. The efficacy of naloxone and the lack of effect of NLX-MET on the almost maximal and bilateral antinociception in non-injured mice suggest that the antinociceptive effects evoked by fentanyl and by high doses of NFEPP occur through the activation of central opioid receptors. Fentanyl ( $144 \mathrm{nmol} / \mathrm{kg}$ i.v.) produced similar effects when mechanical thresholds were measured by a tail pressure test in healthy mice ${ }^{24}$. The effects of high doses of NFEPP in non-injured mice may be explained by the HendersonHasselbalch equation, which predicts that at a concentration of $1000 \mathrm{nmol} / \mathrm{kg}$ of NFEPP $\left(\mathrm{pK}_{\mathrm{a}}=6.8\right)$, about $20 \%$ $(200 \mathrm{nmol} / \mathrm{kg}$ ) of the substance will be protonated and capable of activating opioid receptors at $\mathrm{pH}$ 7.4. Our experiments suggest that a high enough fraction of this amount may have permeated the blood-brain-barrier to activate opioid receptors in the brain $(\mathrm{pH}=7.4)$ to produce antinociception. In addition, the route of administration has to be considered. Previous data in rats indicated that s.c. injected NFEPP at high dosages did not induce centrally-mediated side effects, but the actions on pain after i.v. injections where not assessed ${ }^{14,16}$. Furthermore, studies on species differences have demonstrated that variations in structure and expression of opioid receptors between mice, rats and humans can have measurable effects on the mediation and magnitude of analgesia ${ }^{29-32}$.

Mice intratibially inoculated with live B16-F10 melanoma cells develop a local bone tumor with mixed osteoblastic/osteolytic histopathological features accompanied by thermal hyperalgesia ${ }^{21}$. In addition, B16-F10 cells can elicit extracellular acidity, probably due to the expression of the a3 isoform of the vacuolar ATPase proton pump in their plasma membrane ${ }^{19}$. Contrasting with the different potency of the two agonists in mice without injury, NFEPP and fentanyl inhibited tumor-induced thermal hyperalgesia at similar doses. Thus, the administration of either ligand at $30 \mathrm{nmol} / \mathrm{kg}$ completely inhibited hyperalgesia without modifying withdrawal latencies in contralateral, non-injured limbs. These antihyperalgesic effects were antagonized by systemic naloxone $(1 \mathrm{mg} / \mathrm{kg})$. However, peritumoral NLX-MET $(1 \mu \mathrm{g})$ did not modify the effect induced by fentanyl, supporting that its action is mediated centrally as described in rats with peripheral inflammation ${ }^{33}$ and in tumor-bearing mice inoculated with NCTC 2472 cells $^{34}$. The participation of peripheral opioid receptors in the antinociceptive effects of fentanyl has been reported in mice intraplantarly inoculated with B16-F10 cells when mechanical allodynia or spontaneous licking were measured ${ }^{24}$. Our results may be explained by the rapid access of fentanyl to the CNS by both passive diffusion and carrier-mediated processes ${ }^{35}$. In contrast, the antihyperalgesic effects of NFEPP in doses up to $100 \mathrm{nmol} / \mathrm{kg}$ were exclusively mediated peripherally in tumor-bearing mice, since they were completely inhibited by peritumoral NLX-MET. Thus, our results support the notion that the acidity of the tumor environment enables NFEPP to activate local opioid receptors in the injured limb at doses that do not act at opioid receptors in uninjured tissue such as CNS. Although we do not know the exact $\mathrm{pH}$ value of the tumor after the intratibial inoculation of B16-F10 cells in our experiments, it has been shown that these cells can induce acidic environments in the metastatic tissue ${ }^{19}$ and that their subcutaneous injection can lower $\mathrm{pH}$ values down to $5.8^{36}$. Finally, the particular bone milieu, where osteoclasts induce bone resorption through proton release, suggests that very low extracellular $\mathrm{pH}$ values, such as 4.5 , could be reached ${ }^{8}$.

To elucidate the involvement of MOR, DOR and KOR in the inhibition of tumoral hyperalgesia evoked by NFEPP, we tested the effects of the cyprodime, naltrindole and nor-binaltorphimine at doses able to block selectively MOR, DOR and KOR, respectively ${ }^{37,38}$. The efficacy of cyprodime, but not naltrindole and norbinaltorphimine, to revert the effect of NFEPP indicates that the inhibition of tumor hyperalgesia evoked by NFEPP occurs through the activation of MOR exclusively. Thus, although the chemical structure of NFEPP led to an improved binding affinity at low $\mathrm{pH}$ values, its selectivity for MOR seems similar to that of fentanyl, consistent with our initial report ${ }^{14}$.

The efficacy of some drugs to inhibit bone tumor-induced hyperalgesia can depend on the type of neoplastic process $^{20,39}$. Therefore, we also assayed NFEPP's ability to inhibit thermal hyperalgesia in mice inoculated with NCTC $2472^{26}$ or RM1 cells ${ }^{27}$. The effects in mice inoculated with killed NCTC 2472 or RM1 cells confirmed that high doses of NFEPP are needed to produce antinociception in mice without tumors. In mice inoculated with live NCTC 2472 or RM1 cells, NFEPP counteracted thermal hyperalgesia with a similar potency as that observed in mice treated with live B16-F10 cells, demonstrating its efficacy in different types of bone tumors. This is coherent with its mechanism of action, since the main variable involved in the analgesic activity of NFEPP seems related to tissue acidification, a common property of bone tumors independent of the cell line used ${ }^{5}$.

In conclusion, the present data demonstrate that NFEPP can inhibit hyperalgesia by acting at peripheral MOR in the acidic tumoral environment in mice. The activation of central opioid receptors may be due to excessively high doses of NFEPP yielding sufficient amounts of protonated compound to activate opioid receptors at normal $\mathrm{pH}$, and/or to species differences in structure and signaling of opioid receptors ${ }^{29-32}$. Together with the inhibition of enkephalin-degrading enzymes ${ }^{25}$, the blockade of $\mathrm{P} 2 \mathrm{X} 3$ receptors $^{40}$ or the stimulation of endothelin-B receptors ${ }^{41}$, the acid-related antihyperalgesic effect induced by NFEPP adds a new approach to counteract tumoral hyperalgesia through the activation of peripheral opioid receptors. In view of current discussions surrounding the predictivity of animal models in pain research ${ }^{42}$, it will be particularly important to examine the effects of NFEPP in humans. 


\section{Methods}

Animals. Experiments were performed in 5-6 weeks old (26-33 g) C57BL/6 and C3H/He male mice bred in the Animalario de la Universidad de Oviedo (Reg. 33044 13A). Mice were housed in groups of 8-10 per cage, lined with a sawdust bedding, and maintained at $21{ }^{\circ} \mathrm{C}$ and $35 \%$ humidity on a 12 -h dark-light cycle, with free access to food and water. All experimental procedures were approved by the Comité Ético de Experimentación Animal de la Universidad de Oviedo (Asturias, Spain) and performed according to the guidelines of European Communities Council Directive (2010/63/EU) for animal experiments. Each animal was used only once.

Compounds and their administration. NFEPP was synthesized by a contractor (ASCA GmbH, Berlin, Germany) according to our computer-assisted design ${ }^{14}$. It was dissolved in dimethyl-sulfoxide (DMSO; $4 \mathrm{mg} /$ $\mathrm{ml}$ ) at a maximal concentration of $1.75 \%$. Fentanyl citrate (Sigma) was dissolved in $0.9 \% \mathrm{NaCl}$. In order to compare the effects produced by these drugs, the amounts of NFEPP or fentanyl administered are expressed on a molar basis, since fentanyl represents only $63.65 \%$ of the entire molecular weight of the citrate salt. NFEPP (10-1000 nmol/ $/ \mathrm{kg}$ corresponding to $3.6-355 \mu \mathrm{g} / \mathrm{kg})$ and fentanyl $(10-100 \mathrm{nmol} / \mathrm{kg}$ corresponding to $5.3-53 \mu \mathrm{g} /$ $\mathrm{kg}$ of fentanyl citrate) were administered i.v. in a final volume of $5 \mathrm{ml} / \mathrm{kg} 10 \mathrm{~min}$ before testing. The non-selective opioid receptor antagonist naloxone $(1 \mathrm{mg} / \mathrm{kg}$; Tocris), the MOR selective antagonist cyprodime hydrobromide $(1 \mathrm{mg} / \mathrm{kg}$; Sigma) and the respective DOR and KOR antagonists naltrindole hydrochloride $(0.1 \mathrm{mg} / \mathrm{kg}$; Tocris) and nor-binaltorphimine dihydrochloride $(10 \mathrm{mg} / \mathrm{kg}$; Tocris $)$ were dissolved in $0.9 \% \mathrm{NaCl}$ and administered s.c. into a skin fold of the dorsal side of the neck in a final volume of $10 \mathrm{ml} / \mathrm{kg} 30 \mathrm{~min}$ before testing. Naloxone-methiodide (NLX-MET 0.1-1 $\mu$ g; Sigma), a non-selective, peripherally-restricted opioid receptor antagonist ${ }^{22-25}$, was dissolved in $0.9 \% \mathrm{NaCl}$ and injected s.c. $(100 \mu \mathrm{l})$ over the tibial tumoral mass (peritumoral administration) $10 \mathrm{~min}$ before the test. The administration in limbs without tumor was performed s.c. in the calf, the region corresponding to the peritumoral administration in tumor-bearing mice. Control mice received the respective solvents. The selective MOR ligand $\left[{ }^{3} \mathrm{H}\right]$-DAMGO (specific activity $49.2 \mathrm{Ci} / \mathrm{mmol}$, Perkin-Elmer) was used in binding assays.

Binding assays. Untreated C57BL/6 mice were killed by decapitation under light isoflurane anesthesia. Brains without cerebella were removed and homogenized in $5 \mathrm{ml}$ of ice-cold $50 \mathrm{mM}$ TrisHCl (subsequently referred to as buffer) using a PT 3100 Kinematica Polytron coupled to a PT-DA 3012/2 S Homogenizer Generator (Littau, Switzerland) for $20 \mathrm{~s}$, set at $5000 \mathrm{rpm}$. The homogenate was centrifuged (Optima L-90 K Ultracentrifuge, Beckman) at $42,000 \mathrm{~g}$ for $20 \mathrm{~min}$ at $4{ }^{\circ} \mathrm{C}$. The pellet was resuspended in ice-cold buffer ( $\mathrm{pH} 7.4$ ), vortexed and centrifuged as before. The final pellet obtained from a single brain homogenate was suspended again in $6 \mathrm{ml}$ buffer at pH 7.4, briefly homogenized, divided into 3 samples of $2 \mathrm{ml}$ and further centrifuged. The resulting pellets were resuspended in ice-cold buffers at different $\mathrm{pH}$ values $(7.4,6.5$ and 5.5$)$ up to a protein concentration of $2 \mathrm{mg} / \mathrm{ml}^{43}$. For competition studies, $50 \mu \mathrm{l}$ of crude membrane suspensions were incubated in agitation and protected from light at room temperature for $40 \mathrm{~min}$ with $4 \mathrm{nM}\left[{ }^{3} \mathrm{H}\right]$-DAMGO together with buffer only $(100 \%$ binding of $\left[{ }^{3} \mathrm{H}\right]$-DAMGO) or with different concentrations of fentanyl $\left(10^{-10}-10^{-6} \mathrm{M}\right)$, NFEPP $\left(10^{-10}-10^{-6} \mathrm{M}\right)$ or naloxone $\left(10^{-4} \mathrm{M}\right)$ to determine non-specific binding in a final volume of $500 \mu \mathrm{l}$. Separate experiments were performed, in which the $\mathrm{pH}$ of all reagents, membranes and buffer was either 7.4, 6.5 or 5.5. The binding reaction was terminated by rapid filtration of the mixture through Whatman GF/B filters pre-soaked for $30 \mathrm{~min}$ in $0.1 \%$ bovine serum albumin incubation buffer. The filters were washed twice with $5 \mathrm{ml}$ ice-cold buffer and transferred to polyethylene counting vials. Three $\mathrm{ml}$ of scintillation cocktail Optiphase 'Hisafe' 3 (Perkin-Elmer) were added to each vial, which was counted 24 h later by a Wallac 1409 Scintillation Counter (Turku, Finland). All experiments were run in duplicate and repeated 5-6 times. Competition curves were fitted by non-linear regression using the one-site competition fitting option. The total specific binding obtained in the absence of fentanyl or NFEPP was considered the $100 \%$ binding and the concentration of compounds resulting in a $50 \%$ reduction of $\left[{ }^{3} \mathrm{H}\right]$-DAMGO binding $\left(\mathrm{IC}_{50}\right)$ was calculated.

Cell cultures and cell inoculation. B16-F10 melanoma cells (American Type Culture Collection, ATCC) were cultured in Dulbecco's modified Eagle's medium (DMEM; Gibco) enriched with $10 \%$ fetal calf serum (FCS; Gibco). Once preconfluence was reached, cells were treated with trypsin/EDTA $(0.05 \% / 0.02 \%)$ and detached. The trypsin/EDTA solution was recovered, neutralized with DMEM, supplemented with 10\% FCS and centrifuged at $400 \mathrm{~g}$ for $10 \mathrm{~min}$. The remaining pellets were suspended in $\mathrm{PBS}^{20}$.

NCTC 2472 fibrosarcoma cells (ATCC) were cultured in NCTC 135 medium (Sigma) containing 10\% horse serum (Sigma), and were passaged weekly according to ATCC guidelines. When cells were confluent, they were detached by scraping, centrifuged at $400 \mathrm{~g}$ for $10 \mathrm{~min}$, and the remaining pellet was suspended in $\mathrm{PBS}^{26}$.

RM1 prostate carcinoma cells (kindly donated by Dr. Timothy Thompson, MD Anderson Cancer Center, University of Texas) were cultured in DMEM (low glucose) + glutamine (DMEM + GlutaMAX; Gibco) enriched with 10\% FCS (Gibco), HEPES (1 M) (Cellgro), and penicillin (10,000 U/ml)-streptomycin (10 mg/ml) (Biochrom AG). When cells were preconfluent, they were treated with trypsin/EDTA $(0.05 \% / 0.02 \%)$ and detached. The trypsin/EDTA solution was neutralized with growth medium (1:1) and, after centrifugation at $400 \mathrm{~g}$ for 10 min, the remaining pellet was suspended in $\mathrm{PBS}^{27}$.

For surgical procedures, anesthesia was induced by spontaneous inhalation of $3 \%$ isoflurane (Isoflo; Esteve) and maintained by $1.5 \%$ isoflurane in oxygen through a breathing mask. A suspension of $10^{5} \mathrm{~B} 16-\mathrm{F} 10$ cells in $5 \mu \mathrm{l}$ PBS was injected into the right tibial medullar cavity of C57BL/6 mice. Next, acrylic glue (Hystoacril'; Braun) was applied onto the incised area and surgery was completed with a skin stitch. The same procedure was applied in $\mathrm{C} 3 \mathrm{H} / \mathrm{He}$ mice receiving $10^{5}$ NCTC 2472 cells and in C57BL/6 mice inoculated with $10^{3} \mathrm{RM} 1$ cells. 
Control mice were inoculated with the same number of cells previously killed by shock freezing three times without cryoprotection.

Unilateral hot plate test. Thermal withdrawal latencies were measured using the unilateral hot plate (IITC Life Science). As described previously ${ }^{44}$, mice were gently restrained and the plantar side of one hind paw was placed on the hot plate maintained at $49.1 \pm 0.2{ }^{\circ} \mathrm{C}$. The same procedure was performed on the other hind paw. Withdrawal latencies of each paw were measured twice at two-minute intervals, the mean of two measures was calculated, and a cut-off of $30 \mathrm{~s}$ was employed. In order to habituate mice to test environment and to discard abnormal withdrawal reactivity in particular individuals, a measurement of basal latencies was taken in each hind paw at least $5 \mathrm{~h}$ before starting experiments. Our methodological approach was to exclude from the assays those mice exhibiting basal latencies in healthy paws above $20 \mathrm{~s}$ or not showing reduced withdrawal latencies in tumoral paws. However, since no aberrant responses were detected, no animal was discarded for this reason. The experimenter was blinded to the treatments. Based on previous reports, behavioral measures of thermal hyperalgesia were performed 1 week after the intratibial inoculation of B16-F10 cells ${ }^{21}$, and 4 or 2 weeks after the inoculation of NCTC 2472 or RM1 cells, respectively ${ }^{26,27}$.

Statistical analysis. Data were analyzed using the GraphPad Prism version 6.01. All data were normally distributed and of equal variances as assessed by Kolmogorov-Smirnov normality test. In binding experiments, means and standard errors of the means (SEM) of $\mathrm{IC}_{50}$ values for each condition ( $\mathrm{pH}$ value and compound) were calculated. Comparisons between $\mathrm{IC}_{50}$ values were performed by two-way analysis of variance (ANOVA) followed by the Tukey's test. In behavioral studies, the mean and SEM of paw withdrawal latency values were calculated. Comparisons between two groups were made by the unpaired Student's $t$ test for independent data, whereas one-way ANOVA followed by the Dunnett's $t$ test was used to compare effects induced by different doses of compounds in one paw. The effects of different doses of a compound or of different compounds in both paws were assessed by two-way ANOVA followed by the Tukey's test. Statistical significance was considered at $P<0.05$.

\section{Data availability}

All data generated and analyzed during this study are included in this published article. All raw data are available from the corresponding author on reasonable request.

Received: 5 September 2019; Accepted: 15 October 2020

Published online: 29 October 2020

\section{References}

1. Baron, R., Hans, G. \& Dickenson, A. H. Peripheral input and its importance for central sensitization. Ann. Neurol. 74, 630-636 (2013).

2. Richards, N. \& McMahon, S. B. Targeting novel peripheral mediators for the treatment of chronic pain. Br. J. Anaesth. 111, 46-51 (2013).

3. Holzer, P. Acid-sensitive ion channels and receptors. Handb. Exp. Pharmacol. 194, 283-332 (2009).

4. Tabas, I. \& Glass, C. K. Anti-inflammatory therapy in chronic disease: challenges and opportunities. Science 339, 166-172 (2013).

5. Gerweck, L. E., Vijayappa, S. \& Kozin, S. Tumor pH controls the in vivo efficacy of weak acid and base chemotherapeutics. Mol. Cancer Ther. 5, 1275-1279 (2006).

6. Kato, Y. et al. Acidic extracellular microenvironment and cancer. Cancer Cell Int. 13, 89 (2013).

7. Matsumoto, N. et al. Diversity of proton pumps in osteoclasts: V-ATPase with a3 and d2 isoforms is a major form in osteoclasts. Biochem. Biophys. Acta 1837, 744-749 (2014).

8. Teitelbaum, S. L. Bone resorption by osteoclasts. Science 289, 1504-1508 (2000).

9. Lozano-Ondoua, A. N., Symons-Liguori, A. M. \& Vanderah, T. W. Cancer-induced bone pain: mechanisms and models. Neurosci. Lett. 557, 52-59 (2013).

10. Mantyh, P. W. Bone cancer pain: from mechanism to therapy. Curr. Opin. Support. Palliat. Care 8, 83-90 (2014).

11. Zajączkowska, R., Kocot-Kępska, M., Leppert, W. \& Wordliczek, J. Bone pain in cancer patients: mechanisms and current treatment. Int. J. Mol. Sci. 20, 6047 (2019).

12. Jagla, C. A., Martus, P. \& Stein, C. Peripheral opioid receptor blockade increases postoperative morphine demands: a randomized, double-blind, placebo-controlled trial. Pain 155, 2056-2062 (2014).

13. Stein, C. Opioid receptors. Annu. Rev. Med. 67, 433-451 (2016).

14. Spahn, V. et al. A nontoxic pain killer designed by modeling of pathological receptor conformations. Science 355, 966-999 (2017).

15. Rodriguez-Gaztelumendi, A., Spahn, V., Labuz, D., Machelska, H. \& Stein, C. Analgesic effects of a novel pH-dependent $\mu$-opioid receptor agonist in models of neuropathic and abdominal pain. Pain 159, 2277-2284 (2018).

16. Massaly, N., Temp, J., Machelska, H., \& Stein, C. Uncovering the analgesic effects of a pH-dependent mu-opioid receptor agonist using a model of non-evoked ongoing pain [published online ahead of print, 2020 Jun 24]. Pain (2020). doi:https://doi. org/10.1097/j.pain.0000000000001968.

17. Spahn, V. et al. Opioid receptor signaling, analgesic and side effects induced by a computationally designed $\mathrm{pH}$-dependent agonist. Sci. Rep. 8, 8965 (2018).

18. Del Vecchio, G. et al. pKa of opioid ligands as a discriminating factor for side effects [published correction appears in Sci Rep. 2020 Mar 4;10(1):4366]. Sci. Rep. 9, 19344 (2019).

19. Nishisho, T. et al. The a3 isoform vacuolar type $\mathrm{H}^{+}$-ATPase promotes distant metastasis in the mouse B16 melanoma cells. Mol. Cancer Res. 9, 845-855 (2011).

20. Pevida, M. et al. CCL2 released at tumoral level contributes to the hyperalgesia evoked by intratibial inoculation of NCTC 2472 but not B16-F10 cells in mice. N-S. Arch. Pharmacol. 385, 1053-1061 (2012).

21. Curto-Reyes, V. et al. Local loperamide inhibits thermal hyperalgesia but not mechanical allodynia induced by intratibial inoculation of melanoma cells in mice. Cell. Mol. Neurobiol. 28, 981-990 (2008).

22. Brown, D. R. \& Goldberg, L. I. The use of quaternary narcotic antagonists in opiate research. Neuropharmacology 24, 181-191 (1985). 
23. Labuz, D., Mousa, S. A., Schäfer, M., Stein, C. \& Machelska, H. Relative contribution of peripheral versus central opioid receptors to antinociception. Brain Res. 1160, 30-38 (2007).

24. Shinohara, A., Andoh, T., Saiki, I. \& Kuraishi, Y. Analgesic effects of systemic fentanyl on cancer pain are mediated by not only central but also peripheral opioid receptors in mice. Eur. J. Pharmacol. 833, 275-282 (2018).

25. González-Rodríguez, S. et al. Synergistic combinations of the dual enkephalinase inhibitor PL265 given orally with various analgesic compounds acting on different targets, in a murine model of cancer-induced bone pain. Scand. J. Pain 14, 25-38 (2017).

26. Menéndez, L. et al. Initial thermal heat hypoalgesia and delayed hyperalgesia in a murine model of bone cancer pain. Brain Res. 969, 102-109 (2003).

27. Llorián-Salvador, M. et al. Hypernociceptive responses following the intratibial inoculation of RM1 prostate cancer cells in mice. Prostate 75, 70-83 (2015).

28. Dardonville, C. et al. Synthesis and pharmacological studies of new hybrid derivatives of fentanyl active at the mu-opioid receptor and I2-imidazoline binding sites. Bioorg. Med. Chem. 14, 6570-6580 (2006).

29. Huang, Y. H. et al. Morphine produces potent antinociception, sedation, and hypothermia in humanized mice expressing human mu-opioid receptor splice variants. Pain 161, 1177-1190 (2020).

30. Busch-Dienstfertig, M., Roth, C. A. \& Stein, C. Functional characteristics of the naked mole rat mu-opioid receptor. PLoS ONE 8 , e79121 (2013).

31. Nockemann, D. et al. The $\mathrm{K}(+)$ channel GIRK2 is both necessary and sufficient for peripheral opioid-mediated analgesia. EMBO Mol. Med. 5, 1263-1277 (2013).

32. Pasternak, G. W. \& Pan, Y. X. Mu opioids and their receptors: evolution of a concept. Pharmacol. Rev. 65, 1257-1317 (2013).

33. Khalefa, B. I. et al. Relative contributions of peripheral versus supraspinal or spinal opioid receptors to the antinociception of systemic opioids. Eur. J. Pain 16, 690-705 (2012).

34. El Mouedden, M. \& Meert, T. F. The impact of the opioids fentanyl and morphine on nociception and bone destruction in a murine model of bone cancer pain. Pharmacol. Biochem. Behav. 87, 30-40 (2007).

35. Henthorn, T. K., Liu, Y., Mahapatro, M. \& Ng, K. Y. Active transport of fentanyl by the blood-brain barrier. J. Pharmacol. Exp. Ther. 289, 1084-1089 (1999).

36. Delli Castelli, D., Ferrauto, G., Cutrin, J. C., Terreno, E. \& Aime, S. In vivo maps of extracellular pH in murine melanoma by CESTMRI. Magn. Reson. Med. 71, 326-332 (2014).

37. Menéndez, L., Lastra, A., Meana, A., Hidalgo, A. \& Baamonde, A. Analgesic effects of loperamide in bone cancer pain in mice. Pharmacol. Biochem. Behav. 81, 114-121 (2005).

38. Baamonde, A. et al. Effects of the local administration of selective mu-, delta-and kappa-opioid receptor agonists on osteosarcomainduced hyperalgesia. Naunyn Schmiedebergs Arch. Pharmacol. 372, 213-219 (2005).

39. Pevida, M. et al. The chemokine CCL5 induces CCR1-mediated hyperalgesia in mice inoculated with NCTC 2472 tumoral cells. Neuroscience 259, 113-125 (2014).

40. González-Rodríguez, S. et al. Involvement of enkephalins in the inhibition of osteosarcoma-induced thermal hyperalgesia evoked by the blockade of peripheral P2X3 receptors. Neurosci. Lett. 465, 285-289 (2009).

41. Quang, P. N. \& Schmidt, B. L. Peripheral endothelin B receptor agonist-induced antinociception involves endogenous opioids in mice. Pain 149, 254-262 (2010).

42. Borsook, D., Hargreaves, R., Bountra, C., \& Porreca, F. Lost but making progress--Where will new analgesic drugs come from? Sci. Transl. Med. 6, 249sr3 (2014).

43. Bradford, M. M. A rapid and sensitive method for the quantitation of microgram quantities of protein utilizing the principle of protein-dye binding. Anal. Biochem. 72, 248-254 (1976).

44. Menéndez, L., Lastra, A., Hidalgo, A. \& Baamonde, A. Unilateral hot plate test: a simple and sensitive method for detecting central and peripheral hyperalgesia in mice. J. Neurosci. Methods 113, 91-97 (2002).

\section{Author contributions}

A.B. helped to design and perform the experiments, analyze the results and prepare the manuscript. L.M. helped to design and perform the experiments, analyze the results and prepare the manuscript. S.G-R. helped to perform the experiments and prepare the manuscript. A.L. helped to perform the experiments. V.S. helped to design the experiments and prepare the manuscript. C.S. helped to develop the study rationale, design the experiments, analyze the results and prepare the manuscript. H.M. helped to develop the study rationale, design the experiments, interpret the results and prepare the manuscript.

\section{Funding}

IUOPA is supported by Obra Social Fundación Cajastur-Liberbank (Asturias, Spain). The study was supported by grants from the Ministerio de Economía, Industria y Competitividad, Agencia Estatal de Investigación and FEDER (European Union) (SAF2017-86799-R) (to A. B.) and from Bundesministerium für Bildung und Forschung (VIP 0272/03V0364; 01EC1403E; 01EC1403F) (to C.S. and V.S.). C.S. was also supported by the European Commission (FP7-602891-2) and by the Deutsche Forschungsgemeinschaft (STE 477/19-1; Excellence Cluster Math + EXC 2046 AA1-1).

\section{Competing interests}

C.S. is listed as inventor on US patent $14 / 239,461$ and EP 2,801,046. The other authors declare no competing interests.

\section{Additional information}

Correspondence and requests for materials should be addressed to A.B.

Reprints and permissions information is available at www.nature.com/reprints.

Publisher's note Springer Nature remains neutral with regard to jurisdictional claims in published maps and institutional affiliations. 
(c) (i) Open Access This article is licensed under a Creative Commons Attribution 4.0 International cc) License, which permits use, sharing, adaptation, distribution and reproduction in any medium or format, as long as you give appropriate credit to the original author(s) and the source, provide a link to the Creative Commons licence, and indicate if changes were made. The images or other third party material in this article are included in the article's Creative Commons licence, unless indicated otherwise in a credit line to the material. If material is not included in the article's Creative Commons licence and your intended use is not permitted by statutory regulation or exceeds the permitted use, you will need to obtain permission directly from the copyright holder. To view a copy of this licence, visit http://creativecommons.org/licenses/by/4.0/.

(C) The Author(s) 2020 